\title{
Second Language Experience Can Hinder the Discrimination of Nonnative Phonological Contrasts
}

\author{
Jeffrey J. Holliday \\ Department of Korean Language and Literature, Korea University, Seoul, Republic of \\ Korea; Department of Second Language Studies, Indiana University Bloomington, \\ Bloomington, Ind., USA
}

\begin{abstract}
Background/Aims: Many studies have shown that experienced second language (L2) learners are more skilled than novice L2 learners at a variety of L2 tasks, including auditory discrimination between members of L2 phonological contrasts. In this paper we argued that while L2 experience is typically beneficial when comparing the effects of more versus less experience, it is not necessarily beneficial when comparing the effects of some experience versus none. Methods: We compared the perceptual assimilation and discrimination of the Korean sibilant fricatives $/ \mathrm{s}^{\mathrm{h}} /$ and $/ \mathrm{s}^{*} /$ by 3 native Mandarin populations: naïve listeners, novice L2 learners (4-6 weeks of experience), and advanced L2 learners (over 2 years of experience). Results: The perceptual assimilation of $/ \mathrm{s}^{\mathrm{h}} /$ changed as a result of L2 experience, but only in the /a/ context. It is also shown that novice L2 learners were less accurate than the naïve listeners at discriminating between $/ \mathrm{s}^{\mathrm{h}} /$ and $/ \mathrm{s}^{*} /$ but, crucially, only in the /a/ context. Conclusion: The perception of $/ \mathrm{s}^{\mathrm{h}} /$ by L2 learners may be affected by knowledge of the L2 unavailable to naïve listeners, and some aspects of this knowledge may result in a decline in discrimination accuracy after even a very short period of $L 2$ experience.
\end{abstract}

(c) 2016 S. Karger AG, Basel

\section{Introduction}

It is widely recognized that one's native language (L1) has a strong influence on the perception of speech sounds in a second language (L2). For example, early studies of stop perception along synthesized voice onset time continua showed clear differences between listeners whose native language stop system contained a two-way voicing contrast (as in French or Spanish), a two-way aspiration contrast (as in English), or a three-way contrast between voiced, voiceless unaspirated, and voiceless aspirated stops (as in Thai) (Caramazza et al., 1973; Lisker and Abramson, 1970; Williams, 1977). It has also been observed that increased L2 experience can lead to improved

\begin{tabular}{|c|c|}
\hline KARGER & $\begin{array}{l}\text { C) 2016 S. Karger AG, Basel } \\
0031-8388 / 16 / 0731-0033 \\
\$ 39.50 / 0\end{array}$ \\
\hline & \\
\hline
\end{tabular}

Jeffrey J. Holliday

Department of Korean Language and Literature

Korea University, 145 Anam-ro, Seongbuk-gu

Seoul 02841 (Republic of Korea)

E-Mail holliday@korea.ac.kr 
performance on L2 perception tasks (Flege et al., 1997; Ingram and Park, 1997; Levy, 2009b; Tees and Werker, 1984), suggesting that in some cases L1 influence on L2 speech perception can be overcome with sufficient L2 experience.

For example, Levy (2009b) tested the discrimination accuracy on Parisian French vowel contrasts by 3 groups of native English listeners: naïve listeners with no French experience, L2 learners with an average of 3 years of classroom learning but little immersion experience (ModExp), and L2 learners with an average of 8 years of experience (HiExp), including at least 1 year of immersion in a French-speaking environment. It was found that listeners from the HiExp group were overall more accurate than listeners from the ModExp group when the results were averaged across vowel contexts.

Of course, more experienced L2 learners do not always outperform less experienced learners on L2 perception tasks. When the results in Levy (2009b) were broken down by vowel context, it was found that the HiExp listeners were more accurate than the ModExp listeners in discriminating between $/ \mathrm{e} /$ and $/ \mathrm{o} /$, but not between $/ \mathrm{y} /$ and /u/. Thus, even though the HiExp listeners had surely been exposed to many more exemplars of French $/ y /$ and $/ \mathrm{u} /$ than the ModExp listeners, this increased experience did not lead to more accurate discrimination between the two vowel sounds. Other studies that have tested a variety of L2 production and perception abilities (Flege and Liu, 2001; Ingram and Park, 1997; Shea and Curtin, 2011), including even some longitudinal studies (Aoyama et al., 2008; Flege et al., 2006; Holliday, 2015), have found that, in general, more experienced L2 learners perform better than less experienced learners, but sometimes they do not. Crucially, it is rarely, if ever, found that more experienced L2 learners perform worse than less experienced learners.

In the above studies, the effect of L2 'experience' was tested by comparing the performance of learners who varied in terms of length of L2 study (Tees and Werker, 1984), length of residence in the L2 environment (Flege et al., 1997; Ingram and Park, 1997), or both (Levy, 2009b). When L2 experience is operationalized in these ways, however, it is difficult to control for the learners' actual amount of experience with the particular L2 contrast or sounds of interest. Thus, another way to test the effects of L2 experience is to provide it directly in a laboratory setting. In these studies, often called training studies, the amount and type of linguistic input and feedback can be completely controlled, and the effects of L2 experience can be tested within an individual learner.

For example, Strange and Dittmann (1984) successfully trained L1 Japanese learners of English to discriminate between English /r/ and /1/ using a synthetic rock-lock continuum, and found that some listeners were consequently more accurate on the identification and discrimination of stimuli from a synthetic rake-lake continuum. In another classic series of training studies, Logan et al. (1991) and Lively et al. (1993, 1994) examined the effects of talker variability and phonetic environment on the perceptual learning of the same English $/ \mathrm{r} /-/ 1 /$ contrast, and found that perceptual gains were retained even 6 months after training. As another example, Wang et al. (1999) found that L1 English learners of Mandarin could improve in their identification of the 4 Mandarin tones over the course of 2 weeks of high-variability perceptual training, showing that 'the procedure which has been adopted in training the acquisition of non-native segmental contrasts can also be applied at the suprasegmental level' (Wang et al., 1999, p. 3655 ). Of course, the L2 experience provided in training studies is highly controlled and specific to the research questions, and so perceptual gains found in training studies do not necessarily indicate that L2 learners outside the laboratory would similarly improve 
given enough time. Nevertheless, the results of training studies illustrate what may be possible in L2 learners if given the right type and amount of L2 experience.

In summary, cross-sectional, longitudinal, and training studies of L2 learners generally conclude that although increased L2 experience may or may not lead to improved L2 performance, it certainly will not be detrimental. To fully characterize the role of L2 experience in speech perception, however, a further distinction must be drawn between the aforementioned studies, which compared L2 learners with varying levels of experience, and studies that compare L2 learners with nonlearners. That is, the effect of L2 experience on speech perception can be investigated in terms of 'more versus less' or in terms of 'some versus none'. While it is generally accepted that more experienced learners do not perform worse than less experienced learners on L2 perception tasks, the purpose of the current study is to demonstrate that listeners with some L2 experience may perform worse than listeners with none.

The existence of this possibility is predicted by the Perceptual Assimilation Model (PAM; Best, 1995) and its extension to L2 learners, PAM-L2 (Best and Tyler, 2007). According to PAM (Best, 1995), naïve listeners perceive nonnative speech sounds in terms of L1 categories. That is, a nonnative speech sound is either assimilated to an existing L1 category, not assimilated to any existing L1 category, or not perceived as a speech sound. When a nonnative sound is assimilated to an L1 category, its perception is further characterized by its category goodness (i.e. how much it sounds like a member of that L1 category). It is further claimed that discrimination should be poor between two nonnative sounds that are assimilated to the same L1 category (especially if they are both perceived as good exemplars of that category), but discrimination should be accurate when they are assimilated to different L1 categories.

The basic premise of PAM-L2 (Best and Tyler, 2007) is that perceptual assimilation patterns may change with L2 experience because, while naïve listeners assimilate nonnative sounds only based on their perceived gestural proximity to L1 sounds, L2 learners may equate L1 and L2 sounds at the phonological level as well. For example, L2 learners, but not naïve listeners, have access to the L2 lexicon, which may encourage them to perceive contrastive L2 sounds as belonging to different L1 categories and noncontrastive sounds as belonging to the same L1 category. L2 learners are also likely to be aware of how many categories exist in the L2, the phonological distribution of the allophones in each category, and how the sounds in each category are represented orthographically.

This knowledge of the L2 could impact perceptual assimilation in myriad ways. For example, consider again the case of L1 English listeners' perception of French $/ y$ / and /u/. In Levy (2009a), experienced L2 learners of French perceived French /y/ in a bilabial context (i.e. /byp/) as English /u/ significantly more often than naïve listeners did, whereas naïve listeners perceived it as $/ \mathrm{i} /$ or $/ \mathrm{j} \mathrm{u} /$ significantly more often than the experienced L2 learners did. This difference between listener groups was not found in an alveolar context (i.e. /dyt/), however, as both listener groups perceived /y/ as English $/ \mathrm{j} \mathrm{u} /$ or $/ \mathrm{u} /($ and not $/ \mathrm{i} /$ ). Put another way, both naïve listeners and experienced L2 learners perceived French /dyt/ as English /dut/, whereas French /byp/ was perceived as /bip/ by the naïve listeners and as /bup/ by the experienced L2 learners.

Why would the perceptual assimilation of naïve listeners and L2 learners differ in this way? The naïve listeners' behavior could be attributed to acoustic correspondences between French and English: French /y/ is acoustically much more similar to English /i/ than /u/, but because English /u/ is quite fronted in alveolar contexts, such as /dut/, it 
makes sense that French /byp/ and /dyt/ could be perceived as English /bip/ and /dut/, respectively.

The experienced L2 learners' perception of French /byp/ as English /bup/, on the other hand, could be due to their orthographic equivalence: French $/ y /$ is written as $<\mathrm{u}>$, which may bias L2 learners to equate French /y/ with their L1 /u/ category (Levy, 2009a), but the naïve listeners would not be influenced by French orthography, and so their perceptual assimilation patterns probably reflected the acoustic correspondence between French and English vowels more faithfully. Crucially, according to PAM (Best, 1995), this change in perceptual assimilation with L2 learning predicts a parallel change in discrimination accuracy, which is exactly what was found in Levy and Strange (2008): experienced L2 learners made more errors than naïve listeners in discriminating between French $/ \mathrm{u}-\mathrm{y} /$ in the bilabial (but not alveolar) context. While theoretically predicted, the counterintuitive nature of this result warrants further investigation of the effects of L2 experience on changes in perceptual assimilation and discrimination accuracy.

\section{The Current Study}

The scenario to be investigated in the current study is the perception of the Korean fricatives $/ \mathrm{s}^{\mathrm{h}} /$ and $/ \mathrm{s}^{*} /$ by native Mandarin listeners. While many acoustic cues to the Korean $/ \mathrm{s}^{\mathrm{h}} /-\mathrm{s}^{*} /$ contrast have been suggested (see Chang, 2013, for a review), one cue relevant to the current study is the presence of aspiration in $/ \mathrm{s}^{\mathrm{h}} /$, which is significantly reduced when followed by a high vowel. This reduction in aspiration, along with changes in other cues, renders $/ \mathrm{s} /$ and $/ \mathrm{s}^{*} /$ more difficult to correctly identify in high vowel contexts than in low vowel contexts (Holliday, 2014b; Lee and Jongman, 2012). Both $/ \mathrm{s}^{\mathrm{h}} /$ and $/ \mathrm{s}^{*} /$ are claimed to palatalize before $/ \mathrm{i} /$ and $/ \mathrm{j} /$ (Shin et al., 2013, p. 70; Yi, 2012, p. 109), although some studies have suggested that $/ \mathrm{s}^{* /}$ may not palatalize as consistently as / $\mathrm{s}^{\mathrm{h}} /$ does (Baik, 1998; Martin, 1992, p. 28). Thus, it is often observed that Korean $/ \mathrm{s}^{\mathrm{h}} \mathrm{ja} / \mathrm{and} / \mathrm{s}^{*} \mathrm{ja} /$ are acoustically realized as $\left[\mathrm{6}^{\mathrm{h}} \mathrm{a}\right.$ ] and $\left[6^{*} \mathrm{a}\right]$, respectively. The only other sibilant consonants in Korean are its affricates, /t6, t $6^{\mathrm{h}}, \mathrm{t} \mathrm{t}^{*} /$, which can occur in any vowel context and are consistently realized with the same place of articulation.

Mandarin, on the other hand, has unaspirated sibilant fricatives $\left(/ \mathrm{s}, 6, \int /\right),{ }^{1}$ and both unaspirated (/ts, tc, $\mathfrak{t})$ and aspirated $\left(/ \mathrm{ts}^{\mathrm{h}}, \mathrm{t} \mathrm{t}^{\mathrm{h}}, \mathrm{t}^{\mathrm{h}} /\right)$ affricates. ${ }^{2}$ Acoustically, unpalatalized Korean $/ \mathrm{s}^{*} /$ is quite similar to Mandarin /s/ (Kallay and Holliday, 2012), but unpalatalized Korean $/ \mathrm{s}^{\mathrm{h}} /$ does not have an obvious Mandarin analog. It is similar to Mandarin /s/ in that both sounds are dentialveolar sibilant fricatives, but it is also similar to Mandarin $/ \mathrm{ts}^{\mathrm{h}} /$ in that both are dentialveolar aspirated sibilants.

Just as Levy (2009b) found that the perceptual assimilation of French /y/ by naïve English listeners varied according to consonantal context, Holliday (2014a) found that the perceptual assimilation of Korean $/ \mathrm{s}^{\mathrm{h}} /$ and $/ \mathrm{s}^{*} /$ by naïve Mandarin listeners varied

\footnotetext{
${ }^{1}$ While this last sibilant fricative is often described as 'retroflex', articulatory studies of Mandarin sibilants have not shown that it is actually articulated as such (Ladefoged and Wu, 1984; Lee, 1999; Toda and Honda, 2003). In this paper, it will be transcribed as postalveolar $/ \mathrm{J} /$, although it should be noted that this is not to claim that it is identical to English palatoalveolar $/ \mathrm{J} /$, which is transcribed in the same way.

${ }^{2}$ In this paper we assume, following Lu (2014) and Yip (1996), that the alveolopalatal sibilants are phonologically distinct from the dental and postalveolar series. Other analyses support the treatment of the alveolopalatals as derived from other consonant series, such as the velars or dentals (Chao, 1934; Duanmu, 2007).
} 
according to vowel context. In the $/ \mathrm{a} /$ context, $/ \mathrm{s}^{\mathrm{h}} /$ was perceived as an aspirated affricate on $73 \%$ of trials, and as a sibilant fricative on only $25 \%$ of trials. $/ \mathrm{s}^{*} /$, on the other hand, was perceived as a sibilant fricative on $95 \%$ of the $/ \mathrm{a} /$ trials. Even though Korean $/ \mathrm{s}^{\mathrm{h}} /$ is definitely not an affricate (Chang, 2013), the naïve Mandarin listeners may have perceived it as one if the aspiration cue was salient enough to outweigh the lack of a delayed release characteristic of affricates (Ladefoged and Maddieson, 1996, p. 90). Perceptual assimilation differed, however, in high vowel contexts. Most likely due to the limited availability of aspiration and other important cues, in the $/ \mathrm{i} / \mathrm{and} / \mathrm{u} /$ contexts listeners perceived Korean $/ \mathrm{s} /$ as a sibilant fricative in 90 and $80 \%$ of trials, respectively, and $/ \mathrm{s} * /$ as a sibilant fricative in 60 and $96 \%$ of trials, respectively. Thus, to summarize the results, it was only $/ \mathrm{s}^{\mathrm{h}} /$, and only in the $/ \mathrm{a} /$ context, that was perceived as an affricate in the majority of trials. All other fricative-vowel combinations were perceived as fricatives.

According to PAM (Best, 1995), then, the results of Holliday (2014a) predict that naïve Mandarin listeners should be reasonably accurate at discriminating between $/ \mathrm{s}^{\mathrm{h}} \mathrm{a} /$ and $/ \mathrm{s}^{*} \mathrm{a} /$, and less accurate at discriminating between $/ \mathrm{s}^{\mathrm{h}} \mathrm{i} /$ and $/ \mathrm{s}^{*} \mathrm{i} /$, and between $/ \mathrm{s}^{\mathrm{h}} \mathrm{u} /$ and $/ \mathrm{s}^{*} \mathrm{u} /$. By extension, we might expect L1 Mandarin learners of Korean to also be more accurate at the discrimination and classification of Korean $/ \mathrm{s}^{\mathrm{h}} /-\mathrm{s} * /$ before $/ \mathrm{a} /$ than before $/ \mathrm{i} /$ or $/ \mathrm{u} /$. In a separate experiment, however, L1 Mandarin learners of Korean were found to be very poor at identifying Korean $/ \mathrm{s}^{\mathrm{h}} /$ and $/ \mathrm{s}^{*} /$ in 5 different vowel contexts, with overall accuracy not different from chance and no significant differences between vowel contexts (Holliday, 2014b). While the identification of L2 sounds is likely to be more difficult than merely discriminating between them, this set of results suggests one of at least 3 possible explanations.

First, it could be that naïve Mandarin listeners are not very accurate at discriminating between Korean $/ \mathrm{s}^{\mathrm{h}} /$ and $/ \mathrm{s} * /$ in any vowel context, demonstrating, contra PAM (Best, 1995), that perceptual assimilation patterns do not necessarily predict discrimination ability. It would then come as no surprise that L1 Mandarin learners of Korean were also poor at discriminating between $/ \mathrm{s}^{\mathrm{h}} \mathrm{a} /$ and $/ \mathrm{s}^{*} \mathrm{a} /$, and that their classification accuracy of Korean $/ \mathrm{s}^{\mathrm{h}} /$ and $/ \mathrm{s}^{*} /$ would be equally poor in all vowel contexts.

Second, it could be that both naïve Mandarin listeners and L1 Mandarin learners of Korean are accurate at discriminating between Korean $/ \mathrm{s}^{\mathrm{h}} \mathrm{a} /$ and $/ \mathrm{s}^{*} \mathrm{a} /$, but that the L2 learners of Korean in Holliday (2014b) had not yet learned to map the acoustic cues that differentiate $/ \mathrm{s}^{\mathrm{h}} \mathrm{a} /$ from $/ \mathrm{s}^{*} \mathrm{a}$ / onto their corresponding $\mathrm{L} 2$ category labels. Furthermore, the stimuli in Holliday (2014b) were word-initial CVs extracted from longer words, which could be harder to identify than CVs produced in isolation.

Third, and lastly, it could be that naïve Mandarin listeners are accurate at discriminating between $/ \mathrm{s}^{\mathrm{h}} \mathrm{a} /$ and $/ \mathrm{s}^{*} \mathrm{a} /$, as predicted by PAM (Best, 1995), but that L1 Mandarin learners of Korean are not, the possibility of which is predicted by PAM-L2 (Best and Tyler, 2007). Specifically, if the perceptual assimilation of Korean $/ \mathrm{s}^{\mathrm{h}} /$ and $/ \mathrm{s} *$ / differs between naïve listeners and L2 learners in such a way that naïve listeners perceive them as different $\mathrm{L} 1$ categories and $\mathrm{L} 2$ learners perceive them as the same L1 category, PAM and PAM-L2 predict that the naïve listeners should be more accurate at discriminating between $/ \mathrm{s}^{\mathrm{h}} \mathrm{a} /$ and $/ \mathrm{s}^{*} \mathrm{a} /$ than the L2 learners. Although this third possibility runs counter to the common intuition that listeners with L2 experience should be more accurate on L2 perceptual tasks than listeners without such experience, it is predicted to be possible by both PAM and PAM-L2. This result would also corroborate the findings in Levy (2009b) and Levy and Strange (2008), but for a different L1-L2 combination and segmental contrast. 
Table 1. Gender and age information for each of the 4 listener groups

\begin{tabular}{llll}
\hline Listener group & Female, $\mathrm{n}$ & Male, $\mathrm{n}$ & Median age, years \\
\hline NM & 13 & 5 & 20 \\
Novice MK & 9 & 6 & 24 \\
Advanced MK & 11 & 6 & 24 \\
NK & 12 & 7 & 24 \\
\hline
\end{tabular}

Therefore, the goal of the current study was to test the perceptual assimilation and discrimination of Korean $/ \mathrm{s}^{\mathrm{h}} /$ and $/ \mathrm{s}^{*} /$ by naïve Mandarin listeners and both novice and advanced L1 Mandarin learners of Korean. The results were not expected to support the first hypothesis, which would contradict PAM. It was expected that either the second or the third hypothesis would be supported, although if the results supported the second hypothesis it would need to be explained why the L2 learners were unable to map the acoustic cues to the $/ \mathrm{s}^{\mathrm{h}} /-\mathrm{s} * /$ contrast onto the appropriate category labels. The third hypothesis represented the most straightforward explanation of Holliday (2014a) and Holliday (2014b). In addition, the current study also tested the $/ \mathrm{s}^{\mathrm{h}} / \mathrm{-} / \mathrm{s} * /$ identification accuracy of novice and advanced L1 Mandarin learners of Korean using CVs produced in isolation, to see whether the poor performance of the L1 Mandarin listeners in Holliday (2014b) could have been because the stimuli were CVs extracted from longer words.

\section{Methods}

\section{Participants}

The participants comprised 69 adults recruited from 4 populations (table 1): 18 naïve L1 Mandarin listeners ('NM'), 15 L1 Mandarin novice learners of Korean ('novice MK'), 17 L1 Mandarin advanced learners of Korean ('advanced MK'), and 19 native Korean listeners ('NK'). The NMs were undergraduate students at Indiana University, recruited and tested in Bloomington. All were from mainland China, with a median length of residence in the USA of 5.5 months. The novice MKs were enrolled in an intensive Korean language program at a university in Seoul. At the time of testing these learners had been studying at the beginner level, in a class that presumed no knowledge of Korean whatsoever, for 4-6 weeks. The students were in class for $4 \mathrm{~h}$ /day, 5 days a week. The advanced MKs had all completed an intensive Korean language program at the same university and had since matriculated into the university as regular undergraduate students. The advanced MKs were thus taking a regular undergraduate course load in Korean, with a median length of residence in Seoul of 40 months. Lastly, the NKs were all NK undergraduate students from the same university in Seoul.

As the native Mandarin participants hailed from many different parts of mainland China, some reported speaking another variety of Chinese in addition to Mandarin, such as Cantonese, Xiang, or Wu, but all self-identified as native speakers of Mandarin. All had studied English in school, and a few reported studying an additional foreign language as well, such as Japanese or French. The language backgrounds of the NK speakers were typical of domestic college students in Seoul: all had studied English in school, most reported having studied an additional foreign language as well (e.g. Japanese, Chinese, French, or German), and a few reported having experience studying abroad.

\section{Stimuli}

The experiment consisted of 3 tasks: perceptual assimilation, discrimination, and identification. The stimuli used in all of these tasks were Korean CV syllables produced in the carrier phrase ' $<\mathrm{CV}>$ haseyyo', meaning 'Say $<\mathrm{CV}>$,' by 5 female native speakers of Seoul Korean. The complete stimulus 


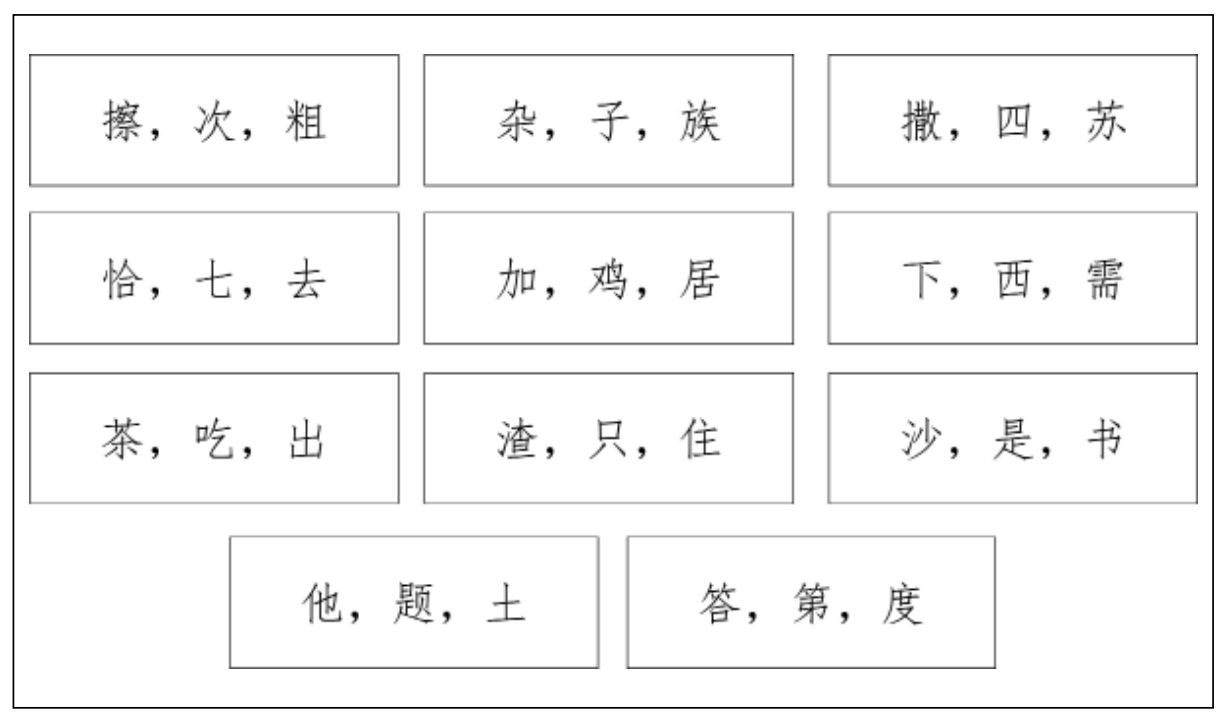

Fig. 1. The screen listeners viewed during the perceptual assimilation task.

set consisted of all Korean consonants paired with all Korean monophthongs. Each speaker produced 2 randomized blocks, with each block containing 1 repetition of each CV. Recordings were done in a sound booth with the CVs presented on a monitor. Subsets of these productions were used as stimuli in the 3 tasks described below.

\section{Procedure}

Participants were tested in a quiet room at their university, seated at a table in front of a laptop computer. The experiment was built and run in OpenSesame (ver. 2.8.1; Mathôt et al., 2012), with stimuli presented through AKG K272 HD headphones. The 3 tasks (perceptual assimilation, discrimination, and identification) were always presented in the same order, but not all groups did all of the tasks. The NKs did not do the perceptual assimilation task, since it presumes native Mandarin phonological categories, and the NMs did not do the identification task, since it presumes knowledge of Korean. The novice and advanced MKs were thus the only groups to do all 3 tasks. All written instructions, both on paper before obtaining informed consent and on screen, were provided in Mandarin for the L1 Mandarin participants and in Korean for the L1 Korean participants.

Perceptual Assimilation

The stimuli for the perceptual assimilation task were a set of CVs composed of a coronal obstruent and one of the vowels $/ \mathrm{a} /, / \mathrm{i} /$, or $/ \mathrm{u} /$. Both repetitions of each sibilant fricative and affricate $\left(/ \mathrm{s}^{\mathrm{h}} /\right.$, $\left./ \mathrm{s}^{*} /, / \mathrm{tt} /, / \mathrm{tc}^{\mathrm{h}} /, / \mathrm{t} \mathrm{t}^{*} /\right)$ and 1 repetition of each coronal stop $\left(/ \mathrm{t} /, / \mathrm{t}^{\mathrm{h}} /, / \mathrm{t}^{*} /\right)$ in each of the 3 vowel contexts yielded 39 tokens per talker. The productions of 4 talkers were used for this task, yielding a total of 156 stimuli, 48 of which were fricatives. The stimuli were blocked by vowel, in the order /a/, /i/, /u/, and the entire perceptual assimilation task was preceded by 5 practice trials.

The NMs were not told what language the stimuli came from, except that it was neither Mandarin nor English, whereas the MKs were told that the stimuli were Korean syllables produced by NK speakers. For each trial, the listener heard a CV token and was then asked to choose the Mandarin consonant that sounded most similar. This selection was made by clicking on one of 11 boxes on the screen, each of which contained 3 Chinese characters representative of a consonant category, as shown in figure 1. The categorization was presented this way to avoid having to use pinyin, a Romanized form of Chinese orthography, which could, especially for the NMs, promote association with English. The 11 Mandarin categories were the 3 sibilant fricatives $(/ \mathrm{s} /, / 6 /, / \mathrm{g} /), 6$ affricates $\left(/ \mathrm{ts} /, / \mathrm{t} /, / \mathrm{tg} /, / \mathrm{s}^{\mathrm{h}} /, / \mathrm{tc}^{\mathrm{h}} /, / \mathrm{t}^{\mathrm{h}} /\right)$, 
and 2 alveolar stops $\left(/ \mathrm{t} /, / \mathrm{t}^{\mathrm{h}} /\right)$. The choices were limited to just these 11 to keep the task as simple as possible, and because previous work has shown that Korean sibilant fricatives and affricates are rarely perceived as anything noncoronal by L1 Mandarin listeners (Holliday, 2014a). For each trial, after choosing a Mandarin category, the listener gave a rating of how similar the stimulus sounded to the chosen Mandarin category. The choices for the similarity rating were 'exactly the same', 'similar, but a little different', and 'very different'. No numbers were presented in association with these choices, and listeners made their selection by clicking a box on the screen.

Discrimination

Next, all participants completed an oddity discrimination task, in which for each trial participants heard 3 consecutive coronal obstruent-initial CVs and were asked to choose the sound that was different from the other two. For all trials either the first $\mathrm{CV}$ was different from the second and third, or the third CV was different from the first and second. The listeners were told that the correct answer would always be either the first or third sound, and the listeners responded by clicking 1 of 2 boxes on the screen that said either 'first' or 'third' in either Mandarin or Korean. Thus, for example, if the CVs presented were $/ \mathrm{s}^{\mathrm{h}} \mathrm{a} /-/ \mathrm{s}^{\mathrm{h}} \mathrm{a} /-/ \mathrm{s}^{*} \mathrm{a} /$, the correct answer would be 'third'. The CVs were presented with an interstimulus interval of $225 \mathrm{~ms}$.

There were 108 trials in total, composed of 40 fricative-fricative trials $\left(/ \mathrm{s}^{\mathrm{h}} / \mathrm{vs} . / \mathrm{s}^{*} /\right), 36$ fricativeaffricate trials $\left(/ \mathrm{s}^{\mathrm{h}} /\right.$ or $/ \mathrm{s}^{*} / \mathrm{vs}$. $/ \mathrm{tc} /, / \mathrm{tc} \mathrm{h} /$, or $\left./ \mathrm{tc}^{*} /\right), 18$ affricate-affricate trials $\left(/ \mathrm{tc} / \mathrm{vs} . / \mathrm{t} 6 \mathrm{~h} /, / \mathrm{tc} / \mathrm{vs}\right.$. $/ \mathrm{tc}^{*} /$, or $\left./ \mathrm{tc}^{\mathrm{h}} / \mathrm{vs} . / \mathrm{t} * /\right)$, and 14 filler trials involving stops. The target trials were balanced across the vowel contexts $/ \mathrm{a} /, / \mathrm{i} /$, and $/ \mathrm{u} /$, except for the fricative-fricative trials, which contained 2 additional trials of both $/ \mathrm{a} /$ and $/ \mathrm{u} /$ to allow for the inclusion of the palatalized versions of both fricatives (i.e. $/ \mathrm{s}^{\mathrm{h}} \mathrm{ja} /, / \mathrm{s} * \mathrm{ja} /$, $/ \mathrm{s}^{\mathrm{h} j \mathrm{u}} /$, and $/ \mathrm{s} * \mathrm{ju} /$ ). These 108 trials were divided across 1 block of 60 trials with multiple talkers and 1 block of 48 trials with a single talker. In the multiple talker block, the $3 \mathrm{CVs}$ were from 3 different talkers (whose stimuli were also used in the perceptual assimilation task), with the order of the talkers constant across trials. The talker in the single talker block was 1 of the 3 talkers in the multiple talker block. Having 2 blocks with different numbers of talkers was done to avoid floor and ceiling effects, in case it would be too difficult to discriminate between productions of multiple talkers or too easy to discriminate between productions of a single talker. The trials within each block were blocked by vowel context (in the order of /a/, /i/, and then $/ \mathrm{u} /$ ).

Identification

Lastly, the MK and NK groups completed a fricative identification task. The stimuli consisted of $1 / \mathrm{s}^{\mathrm{h}} /$ and $1 / \mathrm{s}^{*} /$ token in each of 6 vowel contexts $(/ \mathrm{a}, \Lambda, \mathrm{o}, \mathrm{u}, \mathrm{i}, \mathrm{i} /)$ produced by all 5 talkers, yielding a total of 60 stimuli. For each trial, the listener heard a CV and was asked which fricative it began with. The participant responded by clicking on a box on the screen that contained 1 of the 2 fricatives represented in Korean orthography. The trials were blocked by vowel, but the talkers were randomized within each block.

\section{Analysis}

Each listener's responses from the 3 tasks were recorded in OpenSesame, exported as a data frame, and analyzed in R (ver. 3.1.2; R Core Team, 2014). One NM listener did not finish the discrimination task due to a computer error, and data from $4 \mathrm{NK}$ listeners were discarded because they reported having lived or studied in a foreign country for more than a few weeks. These exclusions resulted in only 17 listeners included in the NM group for the discrimination task, and only 15 listeners included in the NK group for both the discrimination and identification tasks.

\section{Results}

\section{Perceptual Assimilation}

Our research question in the perceptual assimilation experiment was how the different listener groups perceived aspiration in the Korean fricatives. Tables 2 and 3 show the perceptual assimilation patterns of $/ \mathrm{s}^{\mathrm{h}} /$ and $/ \mathrm{s}^{*} /$ for each listener group 
Table 2. Perceptual assimilation of Korean $/ \mathrm{s}^{\mathrm{h}} /$

\begin{tabular}{|c|c|c|c|c|c|c|c|c|c|}
\hline \multirow[t]{2}{*}{ Response } & \multicolumn{3}{|l|}{ NM } & \multicolumn{3}{|c|}{ Novice MK } & \multicolumn{3}{|c|}{ Advanced MK } \\
\hline & $/ \mathrm{a} /$ & $/ \mathrm{u} /$ & /i/ & $/ \mathrm{a} /$ & $/ \mathrm{u} /$ & /i/ & $/ \mathrm{a} /$ & $/ \mathrm{u} /$ & /i/ \\
\hline$/ \mathrm{s}^{\mathrm{h}} /$ & 47.9 & 4.9 & & 10.0 & & & 6.6 & & \\
\hline$/ \mathrm{tc}^{\mathrm{h}} /$ & & & 6.3 & & & 2.5 & & & \\
\hline$/ \mathrm{t}^{\mathrm{h} /}$ & 13.9 & 2.1 & & 5.0 & & & 6.6 & & \\
\hline$/ \mathrm{s} /$ & 30.6 & 91.0 & & 56.7 & 83.3 & & 61.8 & 88.2 & 2.2 \\
\hline$/ 6 /$ & & & 91.7 & & & 96.7 & & & 96.3 \\
\hline$/ \mathrm{d} /$ & 4.9 & 2.1 & & 25.0 & 14.2 & & 23.5 & 11.0 & \\
\hline Other & 2.8 & & 2.1 & 3.3 & 2.5 & 0.8 & 1.5 & 0.7 & 1.5 \\
\hline
\end{tabular}

Cells with a response rate higher than $50 \%$ are in italics.

Table 3. Perceptual assimilation of Korean $/ \mathrm{s} * /$

\begin{tabular}{|c|c|c|c|c|c|c|c|c|c|}
\hline \multirow[t]{2}{*}{ Response } & \multicolumn{3}{|l|}{ NM } & \multicolumn{3}{|c|}{ Novice MK } & \multicolumn{3}{|c|}{ Advanced MK } \\
\hline & $/ \mathrm{a} /$ & $/ \mathrm{u} /$ & /i/ & $/ \mathrm{a} /$ & $/ \mathrm{u} /$ & /i/ & $/ \mathrm{a} /$ & $/ \mathrm{u} /$ & /i/ \\
\hline$/ \mathrm{t}^{\mathrm{h}} /$ & & & 2.1 & & & & & & \\
\hline$/ \mathrm{s} /$ & 86.8 & 92.4 & 2.8 & 75.0 & 83.3 & & 77.9 & 96.3 & 1.5 \\
\hline /6/ & & & 93.8 & & & 99.2 & & & 98.5 \\
\hline $\mid S /$ & 11.1 & 5.6 & & 22.5 & 16.7 & & 20.6 & 2.2 & \\
\hline Other & 2.1 & 2.1 & 1.4 & 2.5 & & 0.8 & 1.5 & 1.5 & 1.5 \\
\hline
\end{tabular}

Cells with a response rate higher than $50 \%$ are in italics.

in each vowel context. There are several trends that hold with very few exceptions. First, / $\mathrm{s} /$ was almost never perceived as aspirated by any listener group in any vowel context. This result was expected, as Korean $/ \mathrm{s}^{*} /$ is known to be accompanied by very little, if any, aspiration in all vowel contexts (Chang, 2013). Second, all listener groups perceived $/ \mathrm{s}^{\mathrm{h}} /$ and $/ \mathrm{s}^{*} /$ as either alveolar or postalveolar in the $/ \mathrm{a} /$ and $/ \mathrm{u} /$ contexts and as alveolopalatal in the /i/ context. The variation in the perceived place of articulation in the $/ \mathrm{a} /$ and $/ \mathrm{u} /$ contexts was also expected. Not only was the same pattern found in Holliday (2014a), but it is also known that the $/ \mathrm{s} /-/ \mathrm{J} /$ contrast is not maintained in many varieties of Chinese, including the widely spoken varieties of Cantonese, $\mathrm{Wu}$, and Min (Norman, 1988; Ramsey, 1987), and some varieties of Mandarin spoken on the mainland (Chen, 1991). Accordingly, such variation in perceived place of articulation should not necessarily be attributed to place variation in Korean $/ \mathrm{s}^{\mathrm{h}} /$ and $/ \mathrm{s}^{*} /$. Further evidence against such an interpretation can be found in Schmidt (2007), who tested L1 English listeners on the same set of stimuli used 


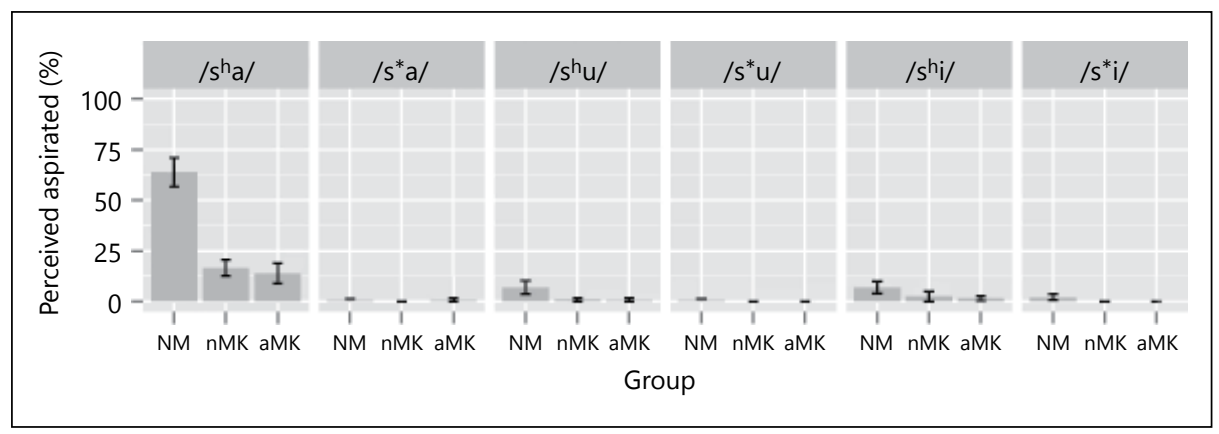

Fig. 2. Percentage of trials for each Korean CV that were assimilated to an aspirated L1 category. $\mathrm{nMK}=$ Novice $\mathrm{MK} ; \mathrm{aMK}=$ advanced MK. Error bars represent $95 \%$ confidence intervals.

by Holliday (2014a) but did not find any evidence for within-vowel variation in the perceived place of articulation of $/ \mathrm{s}^{\mathrm{h}} /$ and $/ \mathrm{s}^{*} /$. Lastly, the perception of $/ \mathrm{s}^{\mathrm{h}} \mathrm{i} /$ and $/ \mathrm{s}^{*} \mathrm{i} /$ as alveolopalatal likely reflects the palatalization of $/ \mathrm{s}^{\mathrm{h}} /$ and $/ \mathrm{s}^{*} /$ before $/ \mathrm{i} /$ (Shin et al., 2013, p. 70; Yi, 2012, p. 109).

Perhaps the only clear difference between the listener groups is that the NM listeners perceived $/ \mathrm{s}^{\mathrm{h}} /$ in the $/ \mathrm{a} /$ context as an aspirated affricate far more often $(61.8 \%)$ than both the novice (15.0\%) and advanced MK listeners (13.2\%). This result for the NM group replicates Holliday (2014a), who found that $/ \mathrm{s} / \mathrm{in}$ the $/ \mathrm{a} /$ context was perceived as an aspirated affricate in $73 \%$ of trials. To further investigate whether the 3 groups here perceived aspiration in the stimuli differently, each response was coded as either aspirated or unaspirated based on the Mandarin category chosen as most similar to the stimulus. Thus, a response of an aspirated affricate $/ \mathrm{t}^{\mathrm{h}}, \mathrm{t}^{\mathrm{h}}, \mathrm{g}^{\mathrm{h}} / \mathrm{or}$ an aspirated stop $/ \mathrm{t}^{\mathrm{h}} /$ was coded as 'aspirated', and a response of a sibilant fricative $/ \mathrm{s}, 6, \mathrm{~J} /$, an unaspirated affricate /ts, tc, $\mathfrak{y} /$, or an unaspirated stop /t/ was coded as 'unaspirated'. Then, for each of the fricative-initial CV stimulus types, the percentage of aspirated responses for each CV was calculated for each individual subject. The group means of the by-subject percentage of tokens perceived as aspirated are shown in figure 2.

Because the individual rates of perceived aspiration were not normally distributed, the results were analyzed using a series of Kruskal-Wallis one-way ANOVAs for each CV, with p values Holm-Šidak corrected for multiple comparisons. Significant differences in the rate of perceived aspiration across listener groups were found only in the perception of $/ \mathrm{s}^{\mathrm{h}} \mathrm{a} /(\mathrm{H}=22.316, \mathrm{p}<0.0001)$. Comparisons between the individual groups were made with Mann-Whitney U tests, also corrected for multiple comparisons, which revealed significant differences between the naïve listeners and both the novice L2 learners $(U=238.5, p<0.001)$ and the advanced $L 2$ learners $(U=276.5, p=$ $0.0001)$. No differences among listener groups were found in the perception of $/ \mathrm{s} * /$, or the perception of $/ \mathrm{s}^{\mathrm{h}} \mathrm{i} /$ or $/ \mathrm{s}^{\mathrm{h}} \mathrm{u} /$.

It should be emphasized that this difference between listener groups in the perception of $/ \mathrm{s}^{\mathrm{h}} \mathrm{a} /$ most likely reflects sensitivity to the aspiration in the stimuli and not to a false percept of affrication. If these results were being driven by perceived affrication, we would expect more unaspirated affricates among the listeners' responses. However, across all listener groups and all CV conditions, unaspirated affricates never accounted for more than $2 \%$ of responses. 
Table 4. Mean accuracy for each trial type for each listener group

\begin{tabular}{lllll}
\hline Listener group & Affricate-affricate & Fricative-affricate & Fricative-fricative & Total \\
\hline NM & $89.2(+2.0)$ & $94.0(-5.3)$ & $65.3(+8.9)$ & 82.7 \\
Novice MK & $89.3(+1.8)$ & $94.3(+0.7)$ & $61.0(-1.9)$ & 82.6 \\
Advanced MK & $90.2(+2.0)$ & $93.1(+1.5)$ & $62.3(-0.2)$ & 81.7 \\
NK & $97.0(-0.3)$ & $97.8(-1.1)$ & $88.6(+7.0)$ & 95.0 \\
Total & 91.3 & 94.7 & 69.0 & \\
\hline
\end{tabular}

The figures in parentheses indicate the change in accuracy when only the /a/ context is considered.

\section{Discrimination}

Our research question for the discrimination task was whether there were differences in accuracy between listener groups, trial types (i.e. affricate-affricate, fricativeaffricate, or fricative-fricative), and vowel contexts. Across all trials, the NK group was overall most accurate $(95.0 \%)$ followed by the NM group $(82.7 \%)$, the novice MK group (82.6\%), and the advanced MK group (81.7\%). Overall, listeners were most accurate on the fricative-affricate trials $(94.7 \%)$, followed by the affricate-affricate trials $(91.3 \%)$, and the fricative-fricative trials $(69.0 \%)$.

Individual listeners' mean discrimination accuracy (collapsed across the single and multiple talker modes) in each vowel context of each trial type was used as the dependent variable. These results were analyzed in the same way as the assimilation results, with a series of Kruskal-Wallis one-way ANOVAs for each combination of trial type and vowel context, with Holm-Šidak-corrected $p$ values. These tests revealed significant differences across groups in the fricative-fricative trials for all 3 vowel contexts $(\mathrm{H}=33.667, \mathrm{p}<0.0001$ for $/ \mathrm{a} / ; \mathrm{H}=24.613, \mathrm{p}<0.001$ for $/ \mathrm{i} / ; \mathrm{H}=18.883, \mathrm{p}<$ $0.01 \mathrm{for} / \mathrm{u} /$ ), but no group differences in the other two trial types. The between-group differences in the fricative-fricative trials were then examined in a series of MannWhitney U tests, also Holm-Šidak corrected for multiple comparisons. In the /i/ and $/ \mathrm{u} /$ contexts, the only significant comparisons were between the NK listeners and each of the native Mandarin groups, with no significant differences among any of the native Mandarin groups. In the /a/ context, however, significant differences were found not only between the NK listeners and each of the native Mandarin groups $(\mathrm{U}=35, \mathrm{p}=$ 0.003 for $\mathrm{NM} ; \mathrm{U}=2.5, \mathrm{p}<0.0001$ for novice $\mathrm{MK} ; \mathrm{U}=8.5, \mathrm{p}<0.0001$ for advanced MK), but also between the naïve listeners and the novice learners $(U=204, p=0.033)$.

These results are summarized in table 4, which shows the mean accuracy for each trial type for each listener group, collapsed across all vowel contexts. The numbers in parentheses indicate the change in accuracy when only the /a/ context is considered. Thus, while the difference in accuracy on the fricative-fricative trials between the NM and novice MK groups is only $4.3 \%$ when collapsed across vowel contexts, the difference increases to $15.1 \%$ when only the /a/ context is considered.

\section{Identification}

Overall identification accuracy was $53.2 \%$ for the novice MK listeners, $64.1 \%$ for the advanced MK listeners, and $94.6 \%$ for the NK listeners. A Kruskal-Wallis one-way ANOVA confirmed a significant difference among the 3 listener groups $(\mathrm{H}=$ 175.05, $\mathrm{p}<0.0001$ ), with Mann-Whitney $\mathrm{U}$ tests for each between-group comparison 


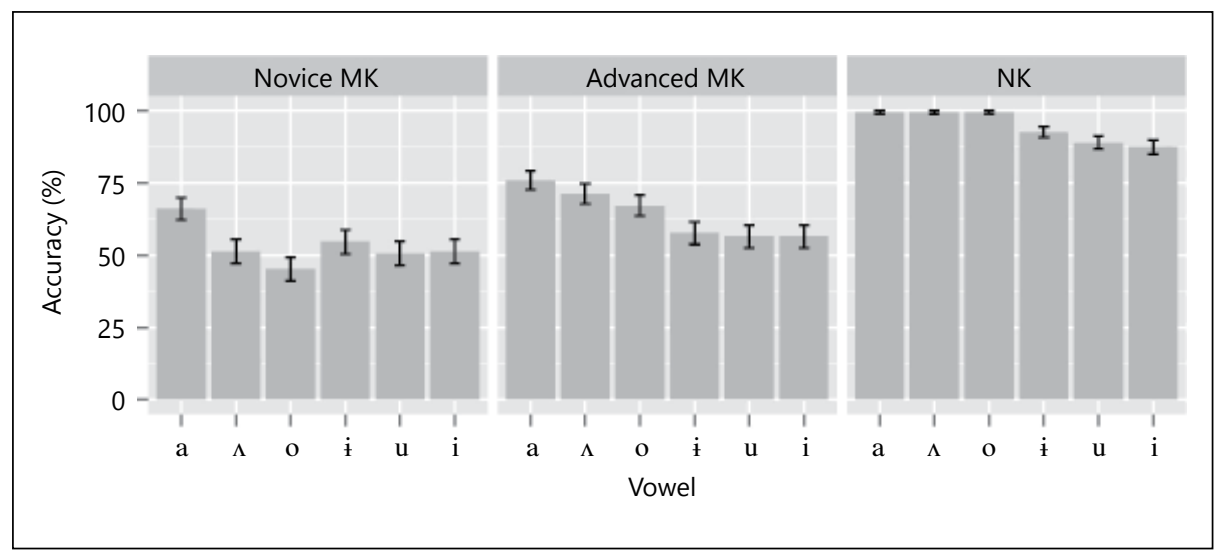

Fig. 3. Identification accuracy across vowel contexts and listener groups. Error bars represent $95 \%$ confidence intervals.

significant as well (all comparisons $U>295, \mathrm{p}<0.001$ ). Identification accuracy broken down by listener group and vowel context is shown in figure 3 . Within each listener group, there were significant differences among vowel contexts only among the native Korean listeners $(\mathrm{H}=53.14, \mathrm{p}<0.0001)$, who were more accurate in the $/ \mathrm{a} / \mathrm{/} / \mathrm{N} /$, and $/ \mathrm{o} /$ contexts than in both the $/ \mathrm{i} /$ (all comparisons $\mathrm{U}=325.5, \mathrm{p}<0.0001$ ) and $/ \mathrm{u} / \mathrm{con}-$ texts (all comparisons $\mathrm{U}=307, \mathrm{p}<0.001$ ). No differences among vowel contexts were found in either of the L2 learner groups.

These results generally replicate the results of Holliday (2014b). In that study, the mean identification accuracy of L1 Mandarin listeners (who had a bit more L2 experience than the novice MK listeners in the current study) hovered between 49 and 56\%, depending on vowel context. The novice MK listeners in the current study fell within this range, and the advanced MK listeners were slightly above it. These results thus indicate that the relatively poor identification accuracy of the L2 listeners in Holliday (2014b) probably cannot be attributed to the elicitation method of the stimuli. These results further confirm that improvement in the identification accuracy of Korean fricatives may be very slow, as the $2 \mathrm{MK}$ groups in the current study were separated, on average, by more than 3 years of immersion experience, and yet the advanced listeners' mean identification accuracy was still less than $65 \%$.

The results from the NK listeners also replicate those of Holliday (2014b), in that while overall identification accuracy was very high, significant differences were found between high and nonhigh vowel contexts. In Holliday (2014b), it was also found that L1 Korean listeners were more accurate in the $/ \mathrm{a} /, / \varepsilon /$, and $/ \mathrm{o} /$ contexts than in the $/ \mathrm{u} /$ and $/ \mathrm{i} /$ contexts. In both studies, identification accuracy before $/ \mathrm{a} /$ is near $100 \%$, with other nonhigh vowels not far behind. In Holliday (2014b) accuracy before /u/ and /i/ was 76.9 and $79.1 \%$, respectively, which is a bit lower than the rates reported here ( 88.9 and $87.4 \%$, respectively; fig. 3). For the NK listeners, then, it may be possible that the low identification accuracy rates in Holliday (2014b) could have been due to how the stimuli were elicited. Taken together, these two studies seem to point to an accuracy rate somewhere in the $80-90 \%$ range for the $/ \mathrm{u} /$ and $/ \mathrm{i} /$ contexts, and near ceiling for the $/ \mathrm{a} /, / \varepsilon /$ and $/ \mathrm{o} /$ contexts. 


\section{General Discussion}

Taken together, the results from the 3 tests presented here generally support the third hypothesis offered in the Introduction: among L1 Mandarin listeners, the perceptual assimilation of Korean sibilant fricatives differs between those who are naïve to Korean and those who are L2 learners of Korean (PAM-L2; Best and Tyler, 2007), and these differences in perceptual assimilation predict these listener groups' discrimination ability (PAM; Best, 1995), which results in naïve listeners being more accurate at the discrimination of Korean sibilant fricatives than novice L2 learners of Korean. The key evidence in support of this interpretation is the fact that the naïve listeners were more accurate at discrimination than the novice L2 learners only in the /a/ context, which was the only context in which the perceptual assimilation patterns would predict such a difference in performance.

The naïve listeners were not shown to be more accurate at discriminating between $/ \mathrm{s}^{\mathrm{h}} \mathrm{a} /$ and $/ \mathrm{s}^{*} \mathrm{a} /$ than the advanced L2 learners, even though they assimilated $/ \mathrm{s}^{\mathrm{h}} \mathrm{a} /$ and $/ \mathrm{s} * \mathrm{a} /$ to different Mandarin categories more often than the advanced L2 learners did. This finding could be interpreted as evidence against PAM's claim that perceptual assimilation patterns predict discrimination accuracy, but it should be noted that the advanced L2 learners were also not any more accurate at discrimination than the naïve listeners either, despite having had substantially more experience with the L2. In other words, even with approximately 3 years of L2 immersion experience, the advanced L2 learners were no more accurate than naïve listeners who had never studied Korean.

These results raise another question that the current study cannot answer: why might the perceptual assimilation of Korean $/ \mathrm{s}^{\mathrm{h}} /$ change in response to L2 learning? Best and Tyler (2007) argued that while the perceived equivalence between nonnative and L1 sounds for a naïve listener must be on the phonetic level, for an L2 learner the perceived equivalence could occur at multiple levels. For example, in the current study, the naïve listeners based their perceptual assimilation judgments on the phonetic properties of the stimuli, possibly modulated by L1 phonotactics. For the L2 learners, however, the perceived equivalence of Korean $/ \mathrm{s}^{\mathrm{h}} /$ to a Mandarin category could be based on phonetic, phonological, or orthographic properties of Korean $/ \mathrm{s} /$. The latter 2 properties of Korean $/ \mathrm{s}^{\mathrm{h}} /$ and $/ \mathrm{s}^{*} /$ would be completely unavailable to a naïve listener, and so differences in perceptual assimilation between the 2 listener groups could be a reflection of the influence of these properties.

It has been claimed (Best and Tyler, 2007; Bundgaard-Nielsen et al., 2011, 2012) that the acquisition of L2 vocabulary is what drives learners to 'rephonologize' their perception of L2 sounds. However, while learning new words most certainly exerts pressure on the L2 learner to perceive a difference between contrastive sounds, the results of the current study illustrate how complicated the picture can be. It is important to note that both here and in Holliday (2014a), the naïve listeners did not assimilate Korean $/ \mathrm{s}^{\mathrm{h}} \mathrm{a} /$ to their Mandarin $/ \mathrm{ts}^{\mathrm{h}} /$ or $/ \mathrm{t}^{\mathrm{h}} /$ categories $100 \%$ of the time: crucially, in both studies, listeners sometimes assimilated it to their Mandarin /s/ category. Thus, based on phonetic cues alone, a novice L2 learner should not be absolutely committed to perceiving it as one category or another. There were several 'candidate' categories to which the L2 learner could have rephonologized his or her perception of $/ \mathrm{s}^{\mathrm{h}} /$. If it were only L2 vocabulary that were pressuring the learner in this domain, we would expect learners to abandon the /s/ percept (since they perceive Korean $/ \mathrm{s} *$ / as Mandarin $/ \mathrm{s} /$ much more consistently) and attune more to the cue in $/ \mathrm{s}^{\mathrm{h}} /$ that naïve listeners were 
already sensitive to (be it aspiration, voice quality, or any other cue discussed in Chang, 2013) that makes it sound like an aspirated affricate. That expectation, however, was not borne out in the results here.

Alternatively, it could be argued that as L2 learners are faced with the task of learning vocabulary they pay less attention to the acoustic differences between the members of L2 contrasts, which would explain the decrease in discrimination accuracy in L2 learners found here. This line of reasoning is similar to what has been proposed for why children's sensitivity to nonnative contrasts decreases with the onset of L1 word learning (Stager and Werker, 1997; Werker et al., 1998). While this explanation is certainly plausible, it does not explain the direction of the change in the L2 learners' perceptual assimilation observed here: that is, why do we not see some of the L2 learners shift their assimilation of Korean $/ \mathrm{s}^{\mathrm{h}} /$ to Mandarin $/ \mathrm{s}^{\mathrm{h}} /$, instead of them all shifting it to a Mandarin sibilant fricative? Thus, what is in need of explanation is the direction of the change in perceptual assimilation observed here. Why did the L2 learners shift their perception of $/ \mathrm{s}^{\mathrm{h}} \mathrm{a}$ / from being ambiguous between a fricative and an affricate (and ambiguous with respect to aspiration) to being just an unaspirated fricative? In the following sections we speculate on 3 possible sources of bias that could be explored in future work.

\section{Different Phonetic Realizations of the $/ s^{h} /-/ s^{*} /$ Contrast $^{3}$}

Although the $/ \mathrm{s}^{\mathrm{h}} /-/ \mathrm{s}^{*} /$ contrast is acoustically distinct word-initially before nonhigh vowels, it is far less so in other phonological environments. In support of this claim is the current finding that $\mathrm{NK}$ listeners are significantly less accurate at identifying word-initial $/ \mathrm{s}^{\mathrm{h} /}$ and $/ \mathrm{s} * /$ before $/ \mathrm{i} /$ and $/ \mathrm{u} /$ than before $/ \mathrm{a} /, / \mathrm{N} /$, and $/ \mathrm{o} /$. In some other environments, $/ \mathrm{s}^{\mathrm{h}} /$ and $/ \mathrm{s} * /$ are totally neutralized: in postobstruent position (e.g. $/$ paks $^{\mathrm{h}} \mathrm{a} /$ 'doctor'), $/ \mathrm{s}^{\mathrm{h}} /$ is phonetically realized as [s*] (i.e. [paks*a]), and in coda position both $/ \mathrm{s}^{\mathrm{h}} /$ and $/ \mathrm{s}^{*} /$ are phonetically realized as unreleased $[\overrightarrow{\mathrm{t}}]$. To the L2 learner of Korean, then, the distinction between $/ \mathrm{s}^{\mathrm{h}} /$ and $/ \mathrm{s}^{*} /$ may only be perceptually robust in a small portion of tokens present in the input. Based on the rest of the input, an L1 Mandarin listener who can perceive a difference between word-initial $/ \mathrm{s}^{\mathrm{h}} \mathrm{a} /$ and $/ \mathrm{s}^{*} \mathrm{a} /$ may nevertheless conclude that $/ \mathrm{s}^{\mathrm{h}} /$ and $/ \mathrm{s}^{*} /$ are not so different from each other. Since the phonetic realization of $/ \mathrm{s} * /$ is much more consistent (and typically assimilated to the Mandarin /s/ category), an L2 learner may begin to equate Korean $/ \mathrm{s}^{\mathrm{h}} /$ with Mandarin /s/, as well. In this way, Korean /s/ , being acoustically similar to both Mandarin /s/ (by virtue of it being a fricative) and Mandarin $/ \mathrm{ts}^{\mathrm{h}} /$ (by virtue of it being aspirated), could shift to being perceived primarily as a sibilant fricative.

\section{Orthography}

It is well known that orthography may guide both the production (Altenberg and Vago, 1983; Hong et al., 2014) and perception (Detey and Nespoulous, 2008) of L2 speech. As pointed out by Bassetti (2006, p. 97), 'instructed second language learners are exposed to orthographic representations without mastering the L2 phonology, and much of the input they receive may be written rather than spoken'. In the case of L2 learners of Korean, then, we might expect effects of orthography to work in at least 2 different ways.

First, the Korean orthography (Hangul) should be unfamiliar to anyone who has not studied Korean, as it is not used to write any other language. The effect of

${ }^{3}$ The author would like to thank an anonymous reviewer for suggesting this idea. 
unfamiliar orthography on the perception of L2 phonological contrasts has typically been investigated in the context of heretofore naïve listeners' ability to phonologically encode the contrast in a word-learning task. One such study, Showalter and HayesHarb (2015), found that listeners were unable to learn the Arabic /k/-/q/ contrast in words when presented in an unfamiliar orthography (Arabic), even when listeners were explicitly shown how the graphemes that represented the contrast differed from each other. However, they also found that listeners were no more accurate even when the word learning was done in a familiar orthography (Latin), suggesting that when the phonological contrast is difficult enough, it may not matter whether the orthography is familiar or not.

Results from Mathieu (2015), however, showed that unfamiliar orthography can have an inhibitory effect on the learning of an L2 phonological contrast. It was further suggested that the effect of unfamiliar orthography may be played out at the level of individual graphemes. For example, an individual unfamiliar grapheme could inhibit learning if it is similar enough to an L1 grapheme such that it promotes an unhelpful association with an L1 phonological category. It should be noted, however, that in both Showalter and Hayes-Harb (2015) and Mathieu (2015) the effect of unfamiliar orthography was mostly considered with respect to differences between the L1 and L2 orthographies, and not whether learners might make inferences about the L2 phonological system based on similarities of individual L2 graphemes to each other.

For interpreting the results of the current study, then, it may be worthwhile to consider the fact that while Hangul itself may not promote the association between Korean and Mandarin sounds, it does contain cues to relationships among Korean sounds themselves. For example, the graphemes for the members of the well-studied 3-way stop contrast suggest that all 3 are related: the lenis alveolar stop $<\sqsubset>$ is the 'base' sound, the fortis stop is written as a geminate of the lenis stop, $<\subset \subset>$, and the aspirated stop is written as the lenis stop with an additional stroke, $<E>$. The velar stops follow the same pattern, with $\langle\neg>$ for the lenis stop, $\langle ר>$ for the fortis stop, and $<\neg>$ for the aspirated stop. Although the Korean sibilant fricative contrast is a 2-way contrast, the graphemes follow the pattern of the lenis and fortis stops: $\langle\boldsymbol{\curlywedge}\rangle$ for $/ \mathrm{s}^{\mathrm{h}} /$ and $\langle\boldsymbol{\mu}\rangle$ for $/ \mathrm{s} * \%$.

For the L2 learner of Korean, this orthographic paradigm may enforce the belief that $/ \mathrm{s}^{\mathrm{h}} /$ and $/ \mathrm{s}^{*} /$ are, on some level, the same type of sound, and could serve to discourage L2 learners from thinking they are as acoustically distinct as naïve listeners perceive them to be, perhaps in the same way that distinct L2 graphemes may help L2 learners encode phonological contrasts into the lexicon more easily (Cutler et al., 2006, p. 280; Escudero et al., 2008). Thus, a question that could be addressed in future work is whether L2 learners of Korean could learn the $/ \mathrm{s} / /-\mathrm{s}^{*} /$ contrast more easily if the graphemes for these sounds were more distinct.

Second, the potential role of Romanization in influencing L2 learners of Korean should be considered as well. Many previous studies have investigated how orthography can mediate learners' perception of L2 sounds when the L1 and L2 orthographies share common graphemes. While L2 learners do not always rely on L1 graphemephoneme correspondences, it has been shown that these correspondences can lead L2 learners to produce or perceive sounds in ways that L1-L2 acoustic correspondences do not predict. For example, Bassetti (2006) found that L1 English novice learners produced the Mandarin triphthong [uei] differently depending on how it is spelled in pinyin: when it is spelled as $<$ ui $>$ (as in [suei] $<$ sui $>$ ) it is much more likely to be produced 
as [ui], deleting the middle vowel [e], but when it is spelled as $<$ wei $>$ (as in [uei], with no onset) the $[\mathrm{e}]$ is retained.

Of course, the question more relevant to the present study is whether these L1 English listeners would actually perceive the triphthong in [suei] and [uei] differently when presented simultaneously with the orthographic prompts $<$ sui $>$ and $<$ wei $>$. Escudero and Wanrooij (2010) addressed a similar question, in testing whether L1 Spanish learners of Dutch would classify Dutch vowels differently depending on whether the responses were elicited auditorily or orthographically. They found that there were significant differences between the two testing conditions, suggesting that in the typical course of L2 acquisition there is room for orthographic influence on the perception of individual L2 phonemes, which could partially explain the shift in perceptual assimilation between the naïve listeners and novice L2 learners found here.

In the current study, although Hangul would have been an unfamiliar orthography, the L2 learners would also have had exposure to Romanized Korean. All of the L1 Mandarin participants in the current study were from mainland China, where the pinyin system of Romanization is introduced at a young age and used continually through adulthood, as it is the primary method of Chinese language input in computers and smartphones. All of the participants had studied English as part of their formal education, as well. Although Romanized Korean was not taught as part of the curriculum in the L2 learners' classrooms, it was introduced at the very beginning of their textbook alongside Hangul, ostensibly to help the learners remember which sound each Hangul grapheme represented. In the textbook used by the learners in the current study, $/ \mathrm{s}^{\mathrm{h}} /$ was introduced as $\left\langle\mathrm{s} / \mathrm{s}>\right.$, and $/ \mathrm{s}^{*} /$ as $\left\langle\mathrm{s}^{*}>\right.$ (Korean Language and Culture Center, 2008, $\mathrm{p}$. 12). It is not clear exactly how an L1 Mandarin learner would interpret $\langle\mathrm{s} / 6\rangle$ or $\langle\mathrm{s} *\rangle$, but the inclusion of $<\mathrm{s}>$ in the transcriptions for both fricatives probably did not discourage the learners from concluding that the sounds are similar both to each other and to Mandarin and English /s/.

Another potential avenue for the influence of Romanized Korean would be through public signage. In Seoul, place names on many signs, including all public transportation signage, include a Romanized transliteration. In the case of a novice L2 learner of Korean, who for the first few weeks of learning may be more comfortable reading Romanized Korean than Hangul, the ubiquitous representation of Korean in Latin letters may reinforce certain L2-to-L1 (i.e. Korean-to-Mandarin) sound correspondences. Specifically, in the Revised Romanization system adopted by the Korean government (National Institute of the Korean Language, 2014), $/ \mathrm{s}^{\mathrm{h} /}$ and $/ \mathrm{s}^{*} /$ are represented as $<\mathrm{s}>$ and $<$ ss $>$, respectively. Thus, when a novice L2 learner of Korean sees words like 'Seoul' and 'Samsung' written side-by-side in Hangul and English, the learner may presume that the first sound in both of those words, $/ \mathrm{s}^{\mathrm{h}} /$, is equivalent to pinyin $<\mathrm{s}>$, which would promote an association with Mandarin $/ \mathrm{s} /$.

\section{Sino-Korean Cognates}

Another potential source of perceptual bias may be found in Sino-Korean cognates. Most of the Korean lexicon consists of loans from Middle Chinese, although the proportion of Sino-Korean words among the most 'basic vocabulary' is substantially lower (Martin, 1992, p. 94). Still, even among the very first words that an L2 learner of Korean would encounter, there are several high-frequency items that would reinforce the idea that Korean $/ \mathrm{s} /$ is not an affricate. In the textbook used by the MK listeners, there were 11 Sino-Korean words beginning with $/ \mathrm{s}^{\mathrm{h}} /$ introduced in the first 
four lessons, but the Mandarin cognate for each of them began with a sibilant fricative (/s/, /6/, or $/ \mathrm{g} /$ ). Perhaps the most obvious Sino-Korean cognates for a beginning L2 learner would be the Sino-Korean numerals. Among them, Korean $/ \mathrm{s}^{\mathrm{h}} \mathrm{am} /$ 'three' and $/ \mathrm{s}^{\mathrm{h}} \mathrm{a} /$ 'four' bear obvious resemblance to the Mandarin cognates, /san/ and /si', both of which begin with /s/ in Mandarin.

Of course, as with the issues related to orthography discussed above, the mere existence of these Sino-Korean cognates alone probably could not bias listeners to change their perception of Korean $/ \mathrm{s}^{\mathrm{h}} \mathrm{a} /$ so drastically. Again, if the naïve listeners in the current study or in Holliday (2014a) never perceived Korean $/ \mathrm{s}^{\mathrm{h}} \mathrm{a} /$ as Mandarin $/ \mathrm{s} /$, then the claim that orthography or cognates could trigger such a shift in perception might be untenable. But, instead, the initial state of the novice L2 learners was one in which Korean $/ \mathrm{s}^{\mathrm{h}} \mathrm{a} /$ was sometimes perceived as an affricate and sometimes as a fricative. In this case, then, a shift in perception in one direction or another may only need the gentle push that orthography or cognates could provide. These claims should be tested in future studies, which would deepen our understanding of how acoustic information interacts with top-down information in the formation of L2 phonological categories.

\section{Conclusion}

In summary, the current study has presented a case in which naïve listeners were more accurate at the discrimination of a nonnative contrast than novice L2 learners of the language. Although the result seems counterintuitive, it is argued that such a scenario is predicted as theoretically possible by PAM (Best, 1995) and PAM-L2 (Best and Tyler, 2007). In the speech perception literature, 'L2 experience' is typically operationalized as phonetic input or some variable, such as length of residence, that is presumed to reflect the amount of phonetic input the L2 learner has received. Typical L2 experience outside of the laboratory, however, is multifaceted, comprising not just linguistic input, but also explicit metalinguistic instruction and exposure to written language. We believe the results of this study highlight the need to refine our understanding of how these different aspects of L2 experience may promote or hinder L2 learning.

\section{Acknowledgments}

The author would like to thank the following people for helpful comments at various stages of this work: Mary Beckman, Cynthia Clopper, Isabelle Darcy, Ken de Jong, Goun Lee, Elizabeth McCullough, David Stringer, and the audiences at the 14th Conference on Laboratory Phonology and the 33rd Second Language Research Forum. The author would also like to thank Shin Woo Bong, Shin Ji Young, Kim Ji Young, Shin Yoon Kyoung, Song Keum Sook, and the Korean Language and Culture Center at Korea University for logistical support in Seoul.

\section{References}

Altenberg EP, Vago RM (1983): Theoretical implications of an error analysis of second language phonology production. Lang Learn 33:427-447.

Aoyama K, Guion SG, Flege JE, Yamada T, Akahane-Yamada R (2008): The first years in an L2-speaking environment: a comparison of Japanese children and adults learning American English. Int Rev Appl Ling 46:61-90.

Baik W (1998): On tensity of Korean fricatives (electropalatographic study). Speech Sci 4:135-145. 
Bassetti B (2006): Orthographic input and phonological representations in learners of Chinese as a foreign language. Writ Lang Lit 9:95-114.

Best CT (1995): A direct realist view of cross-language speech perception; in Strange W (ed): Speech Perception and Linguistic Experience: Issues in Cross-Language Research. York, Timonium, pp 171-204.

Best CT, Tyler MD (2007): Nonnative and second-language speech perception: commonalities and complementarities; in Bohn OS, Munro M (eds): Second-Language Speech Learning: The Role of Language Experience in Speech Perception and Production. A Festschrift in Honour of James E. Flege. Amsterdam, Benjamins, pp 13-34.

Bundgaard-Nielsen RL, Best CT, Kroos C, Tyler MD (2012): Second language learners' vocabulary expansion is associated with improved second language vowel intelligibility. Appl Psycholinguist 33:643-664.

Bundgaard-Nielsen RL, Best CT, Tyler MD (2011): Vocabulary size matters: the assimilation of second-language Australian English vowels to first-language Japanese vowel categories. Appl Psycholinguist 32:51-67.

Caramazza A, Yeni-Komshian GH, Zurif EB, Carbone E (1973): The acquisition of a new phonological contrast: the case of stop consonants in French-English bilinguals. J Acoust Soc Am 54:421-428.

Chang CB (2013): The production and perception of coronal fricatives in Seoul Korean: the case for a fourth laryngeal category. Korean Linguist 15:7-49.

Chao Y-R (1934): The non-uniqueness of phonemic solutions of phonetic systems. Bull Inst Hist Philol 4:363-397.

Chen C-Y (1991): The nasal endings and retroflexed initials in Peking Mandarin: instability and the trend of changes. J Chin Linguist 19:139-171.

Cutler A, Weber A, Otake T (2006): Asymmetric mapping from phonetic to lexical representations in second-language listening. J Phonet 34:269-284.

Detey S, Nespoulous J-L (2008): Can orthography influence second language syllabic segmentation? Japanese epenthetic vowels and French consonantal clusters. Lingua 118:66-81.

Duanmu S (2007): The Phonology of Standard Chinese. Oxford, Oxford University Press.

Escudero P, Hayes-Harb R, Mitterer H (2008): Novel second-language words and asymmetric lexical access. J Phonet 36:345-360.

Escudero P, Wanrooij K (2010): The effect of L1 orthography on non-native vowel perception. Lang Speech $53: 343-365$.

Flege JE, Birdsong D, Bialystok E, Mack M, Sung H, Tsukada K (2006): Degree of foreign accent in English sentences produced by Korean children and adults. J Phonet 34:153-175.

Flege JE, Bohn O-S, Jang S (1997): Effects of experience on non-native speakers' production and perception of English vowels. J Phonet 25:437-470.

Flege JE, Liu S (2001): The effect of experience on adults' acquisition of a second language. Stud Second Lang Acquis 23:527-552.

Holliday JJ (2014a): The perceptual assimilation of Korean obstruents by native Mandarin listeners. J Acoust Soc Am 135:1585-1595.

Holliday JJ (2014b): The perception of Seoul Korean fricatives by listeners from five different native dialect and language groups. Korean Linguist 16:91-108.

Holliday JJ (2015): A longitudinal study of the second language acquisition of a three-way stop contrast. J Phonet 50:1-14.

Hong H, Kim S, Chung M (2014): A corpus-based analysis of English segments produced by Korean learners. J Phonet 46:52-67.

Ingram JCL, Park S-G (1997): Cross-language vowel perception and production by Japanese and Korean learners of English. J Phonet 25:343-370.

Kallay J, Holliday JJ (2012): Using spectral measures to differentiate Mandarin and Korean sibilant fricatives. Proc Interspeech 2012:118-121.

Korean Language and Culture Center (2008): Caymi issnunhankwuke (Fun! Fun! Korean). Seoul, Kyobo.

Ladefoged P, Maddieson I (1996): The Sounds of the World's Languages. Malden, Blackwell.

Ladefoged P, Wu Z (1984): Places of articulation: an investigation of Pekingese fricatives and affricates. J Phonet 12:267-278

Lee G, Jongman A (2012): Perceptual cues in Korean fricatives. J Acoust Soc Am 132:1966.

Lee W-S (1999): An articulatory and acoustical analysis of the syllable-initial sibilants and approximant in Beijing Mandarin. Proc 14th Int Congr Phonet Sci, San Francisco, pp 413-416.

Levy ES (2009a): Language experience and consonantal context effects on perceptual assimilation of French vowels by American-English learners of French. J Acoust Soc Am 125:1138-1152.

Levy ES (2009b): On the assimilation-discrimination relationship in American English adults' French vowel learning. J Acoust Soc Am 126:2670-2682.

Levy ES, Strange W (2008): Perception of French vowels by American English adults with and without French language experience. J Phonet 36:141-157.

Lisker L, Abramson AS (1970): The voicing dimension: some experiments in comparative phonetics. Proc 6th Int Congr Phonet Sci, Prague, pp 563-567.

Lively SE, Logan JS, Pisoni DB (1993): Training Japanese listeners to identify English /r/ and /1/. II. The role of phonetic environment and talker variability in learning new perceptual categories. J Acoust Soc Am 94:12421255.

Lively SE, Pisoni DB, Yamada RA, Tohkura Y, Yamada T (1994): Training Japanese listeners to identify English /r/ and /1/. III. Long-term retention of new phonetic categories. J Acoust Soc Am 96:2076-2087. 
Logan JS, Lively SE, Pisoni DB (1991): Training Japanese listeners to identify English /r/ and /1/: a first report. J Acoust Soc Am 89:874-886.

Lu Y-A (2014): Mandarin fricatives redux: the psychological reality of phonological representations. J East Asian Linguist 23:43-69.

Martin SE (1992): A Reference Grammar of Korean. Singapore, Tuttle.

Mathieu L (2015): The influence of foreign scripts on the acquisition of a second language phonological contrast. Second Lang Res DOI: 10.1177/0267658315601882.

Mathôt S, Schreij D, Theeuwes J (2012): OpenSesame: an open-source, graphical experiment builder for the social sciences. Behav Res Methods 44:314-324.

National Institute of the Korean Language (2014): Rules for Romanization. http://www.korean.go.kr/09_new/dic/ rule/rule_roman_0101.jsp.

Norman J (1988): Chinese. Cambridge, Cambridge University Press.

Ramsey SR (1987): The Languages of China. Princeton, Princeton University Press.

R Core Team (2014): R: a language and environment for statistical computing. Vienna, Foundation for Statistical Computing. http://www.R-project.org/.

Schmidt AM (2007): Cross-language consonant identification; in Bohn OS, Munro M (eds): Second-Language Speech Learning: The Role of Language Experience in Speech Perception and Production. A Festschrift in Honour of James E. Flege. Amsterdam, Benjamins, pp 185-200.

Shea CE, Curtin S (2011): Experience, representations and the production of second language allophones. Second Lang Res 27:229-250.

Shin J, Kiaer J, Cha J (2013): The Sounds of Korean. Cambridge, Cambridge University Press.

Showalter CE, Hayes-Harb R (2015): Native English speakers learning Arabic: the influence of novel orthographic information on second language phonological acquisition. Appl Psycholinguist 36:23-42.

Stager CL, Werker JF (1997): Infants listen for more phonetic detail in speech perception than in word-learning tasks. Nature 388:381-382.

Strange W, Dittmann S (1984): Effects of discrimination training on the perception of /r-1/ by Japanese adults learning English. Percept Psychophys 36:131-145.

Tees RC, Werker JF (1984): Perceptual flexibility: maintenance of recovery of the ability to discriminate non-native speech sounds. Can J Psychol 38:579-590.

Toda M, Honda K (2003): An MRI-based cross-linguistic study of sibilant fricatives. Proc 6th Int Semin Speech Product, Sydney, pp 1-6.

Wang Y, Spence MM, Jongman A, Sereno JA (1999): Training American listeners to perceive Mandarin tones. J Acoust Soc Am 106:3649-3658.

Werker JF, Cohen LB, Lloyd VL, Casasola M, Stager CL (1998): Acquisition of word-object associations by 14-month-old infants. Dev Psychol 34:1289-1309.

Williams, L (1977): The perception of stop consonant voicing by Spanish-English bilinguals. Perception and Psychophysics 21:289-297.

Yi C-H (2012): Hankwukeui Phyocwun Palumkwa Hyensil Palum (Korean Standard Pronunciation and Actual Pronunciation). Seoul, Acanet.

Yip M (1996): Lexical optimization in languages without alternations; in Durand J, Laks B (eds): Current Trends in Phonology: Models and Methods. Salford, ESRI, pp 757-788. 